\title{
Knowledge and Practices of safety use of Pesticides among Farm workers
}

\author{
P.Lavanya Kumari ${ }^{1} \&$ K. Giridhar Reddy ${ }^{2}$ \\ ${ }^{I}$ Scientist, Dept. of Statistics, RARS, Acharya NG Ranga Agricultural University, Tirupati, India. \\ ${ }^{2}$ Branch Manager, State Bank of India, Taduku, Andhra Pradesh, India.
}

\begin{abstract}
This paper is focused on level of Knowledge and Practice of safety pesticide use among various farmworkers in agricultural field. Certain level of education and experience has contributed significant knowledge on safety use of pesticides which further has to make them to practice correct methods while applying pesticides. But no such practice has been identified which tells the need of special training to implement known safety measures rather than knowing further. Age and gender have not influenced their knowledge and practice on safety use of pesticides. Interestingly, farm workers who are working in closed farms had more knowledge than those of in open farms but both group of workers are practicing only half of the safety measures which are known to them. Hence, they extremely need a motivational programme rather than awareness programme.
\end{abstract}

Keywords: Pesticide, Knowledge, Practice, Self-reported health symptoms.

\section{Introduction}

As the world population is expected to grow 50 percent over the next 50 years to 9 billion people. This population growth, combined with the diet demands of a wealthier populace, is expected to double world food demand by 2050 [28]. Assuming production, regulation and innovation trends of the past several decades continue, global pesticide production will be 2.7 times higher in 2050 than in 2000, exposing humans and the environment to considerably higher levels of pesticides. The demand for greater agricultural production poses a challenge perhaps as great as global warming.

In addition to their agricultural use in crop protection, pesticides are important public health tools that are used to prevent vector-borne disease and to increase food supplies. However, recent research has shown that pesticides may also have negative impacts on public health. Studies have demonstrated acutely toxic effects at high doses, as well as chronic effects at low levels of exposure [1].

All over the world, the use of pesticides is considered the most attractive method of controlling pests which involves less labour and characterizes higher output per hectare of land. However, extensive use of such pesticides results in substantial health and environmental threats. Being the principle polluters and victims of pollution, farmers are at the top of this risk. The World Health Organization (WHO) and the United Nations Environment Program estimate pesticide poisoning rates of 2-3 per minute, with approximately 20,000 workers dying from exposure every year, the majority in developing countries [5,28].

Researchers have concluded that farm workers in developing countries will continue to use pesticides in increasing quantities because of the lack of alternatives to pesticides, ignorance of the sustainability of pesticide use, and the weak enforcement of regulations and laws on pesticide use [26, 30, 31]. Workers' knowledge of hazards, which must be correct, is important for the prevention of acute and chronic poisoning: erroneous beliefs can seriously impair workers' capacity to protect themselves against the risks of pesticides [14].

Various policies have been designed to protect workers and minimize exposure to pesticide residues. These policies regulate the time of re-entry into fields after the application of certain chemicals and rely extensively on workers to engage in self-protective behavior such as wearing protective clothing to minimize their risk of exposure.

Most of the results showed that farm workers have reasonably good knowledge but it still has to see, to what extent that knowledge is being used practically. It could possibly be the useful study in order to make them not to expose pesticides with improper method of usage.

\subsection{Objectives}

Present study is conducted with the specific objectives as mentioned below.

1. To assess the knowledge of farm workers regarding the use of pesticides

2. To investigate the determinants and predictors of poor or good knowledge

3. To evaluate the field practices with pesticides in relation to the farm workers knowledge

4. To determine the prevalence of self-reported health symptoms related to pesticide exposure. 


\subsection{Hypotheses}

1. Good knowledge is positively associated with the safe use of pesticides among farm workers.

2. Education will be the major factor to practice correct method while using pesticides.

3. Agriculture background will be significant factor to practice correct method while using pesticides

\section{Review of Literature}

Several studies have recognized that pesticide safety education does not prevent much of the serious exposure that causes illness or death; such exposure usually results from working conditions, which are not likely to be under laborers' control [4]. In a context where workers have very limited economic resources, the effectiveness of the policies in reducing environmental risks is questionable. Poverty and unstable economic situations are conditions that may predict increased exposures to various environmental hazards $[12,29]$. These conditions may be associated with, or influence, personal and group processes that directly modify health or risk behavior.

Worker education programs and safe work practices have been emphasized as key components in the regulatory strategy towards pesticide protection for workers [25]. Sadly few, if any, migrant health clinics are capable, in terms of technology, diagnostic protocols, and logistics, of diagnosing pesticide-related illness [4].

Most of the reported symptoms of pesticide use are considered to be common manifestations of acetyl cholinesterase-inhibiting insecticides $[13,19,24]$. These findings require urgent prevention, intervention, and protection to prevent the risk of these symptoms. The organophosphate and carbamate insecticides such as methamidophos and methomyl were commonly used and these are classified as highly hazardous [27]. Restriction in the use of highly toxic pesticides has been considered by some scientists in order to decrease intoxication events $[11,15]$.

It was observed that more than 75 percent women are involved in activities like winnowing, weeding, grading, threshing and cleaning of field farm operations. There are various ill effects and masculoskeletal problems of such postures and in order to minimize the adverse effects of these postural discomfort and hazards, an ergonomic evaluation of occupational and farm activities need to be conducted. Opinion of women must be considered when designing tools and technologies of agricultural and allied implements and also focus on education and extension activities on women [23].

In 1987, with 1,700 worker-related deaths (52per 100,000 workers), agriculture became the most hazardous occupation in the U.S.[6]. In terms of injury and illness, the Bureau of Labor Statistics estimates that there are 12.7 cases per 100 full-time workers per year. Common hazards include: acute injuries (e.g., falling from heights, farm machinery accidents); chronic low-grade back and joint trauma; lack of toilets and safe drinking water; chronic, acute and occasional pesticide exposures; and occupational dermatomes. In particular, the EPA has ranked chemical exposures of agricultural workers as one of the most significant environmental hazards affecting human health in the U.S. [7].

Exposure to pesticide residues can be substantial during an agricultural season; as many as 3,00,000 seasonal workers may experience pesticide-related illnesses during a given year [8]. The few studies that are available on chronic or low-level pesticide exposure suggest that limb-reduction birth defects [22], childhood leukemia [16], brain tumors [9], sterility, spontaneous abortion, and adult lymphomas and lymph sarcomas [2] may be linked to occupational exposure to pesticides. Prolonged low-level exposure to pesticide residues has been associated with an increased risk of various negative health outcomes, including anemia, asthma.

A KAP analysis conducted at Pondicherry, India discloses that, while $70 \%$ of respondent's perceived pesticide spraying affects a person's health, only $40 \%$ were aware that it affects the environment. Two thirds of the respondents $(62 \%)$ were aware that pesticide enters the body through nose and affects lungs. Awareness on other modes of entry was less. Majority (76\%) of them were aware of training programs conducted by government agriculture department on pest management. About $42 \%$ of farmers had good knowledge regarding pesticide. Between $40 \%$ and $70 \%$ of respondents was not using any protective equipment during pesticide spraying. Around $68 \%$ of farmers indiscriminately disposed empty containers while $48 \%$ buried the leftover pesticides. Significant association $(\mathrm{p}<0.05)$ was observed between knowledge of the farmers and their practices related to pesticides [17].

A pesticide safety knowledge test was developed to assess farmer's knowledge related to pesticide safety at two districts of southern Punjab Pakistan. More educated and adult respondents performed better than younger and illiterate. Similarly large land holder scored higher than small landholders, indicating their more access to information and extension. [18]. 


\section{Methodology}

This section deals with the methodology adopted for the study. It includes, research approach, design for the study, the setting, sample and sampling technique, development of the tools, pilot study, data collection procedure and data analysis.

\subsection{Research approach}

Survey method is adopted to determine the knowledge and practice concerning the safety use of pesticides of the farm workers based on proposed objectives.

\subsection{Study area and Population}

The area where the study took place is Yerpedu, a Mandal in Chittoor District of Andhra Pradesh State, India since it has high level of pesticide usage (Chittoor district handbook 2010-11) and there are no previously published studies regarding pesticide knowledge and practice of farm workers. It belongs to Rayalaseema region. It is located $89 \mathrm{KM}$ towards East from District headquarters Chittoor and $499 \mathrm{KM}$ from the State capital Hyderabad towards North. It is located at $13.6^{\circ} \mathrm{N} 79.6^{\circ} \mathrm{E}$. It has an average elevation of 89 meters (295 feet). It is a part of Tirupati and is located near Sri Kalahasti. Yerpedu consists of 97 Villages and 40 Panchayats. Vedulla Cheruvu is the smallest Village and Vikruthamala is the biggest Village. The Major crops are ground nut, rice and sugarcane.

\subsection{Sampling frame}

This was a cross-sectional study that involved farm workers working in open or closed fields (greenhouses), or both, and using pesticides.

\subsection{Sampling technique and sample size}

The technique of stratified random sampling was used to obtain cross-sectional data for this study in Yerpedu Mandal of Chittoor district. 10 villages, approximately $10 \%$ of villages, are selected randomly out of 97 villages. The farms were selected randomly from within the selected villages. As a result, a total of 300 farm workers were selected randomly.

\subsection{Study tool}

Interview Schedule was developed for this study based on the United States Environmental Protection Agency's questions related to safe pesticide use. A pilot study was carried out for 30 farmers and necessary modifications are carried out. The questionnaire contained four sections. The first was the demographic section, which contained questions regarding age, gender, education level, and type of agricultural field (open or closed fields) and years of experience as a farm worker.

The second section was designed to assess participants' knowledge on safety use of pesticides. Participants were asked with eight questions viz., Wearing of protective clothes and gloves, Wearing of special face mask, Not eating, drinking and smoking during the application of pesticides, Reading and following label instructions, Using leftover pesticide solution in the same day, Washing hands after pesticide application, Not keeping the leftover pesticide in drinking container and Washing contaminated clothes separately that could be answered by either 'yes', 'no'. One point was given for each correct answer; no mark has been given to wrong answer.

The third section of the questionnaire consisted of questions related to their practice on safety use pesticides which are asked in the second section. These questions could be answered either 'never' or 'sometimes' or 'always'. No marks for 'never', 1 mark for 'sometimes' and 2 marks for 'always' have been assigned and practice score is calculated accordingly. The last section was designed to record self-reported health symptoms of the farm workers due to pesticide exposure.

\subsection{Statistical analysis}

All data were coded, entered, and then analyzed using the Statistical Package for Social Sciences (SPSS) program, version 20. Descriptive results were expressed as frequencies, percentages for categorical variables, and as means \pm SD for continuous variables. Independent ample t-test, One-way ANOVA, Duncan's Multiple Range Test (DMRT) and Chi-square test $\left(\chi^{2}\right.$-test) were used appropriately to test the significant differences or associations between independent and dependent variables and the important findings are revealed diagrammatically. 


\section{Results and Discussion}

Knowledge and practice scores were calculated as the summation of responses as per the marks allotted in methodology section. Knowledge score is ranging between 1 to 8 whereas practice score is ranging between 1 to 16. Further these scores are converted into percentages for the sake of clear understanding and better interpretation.

The response rate of invited participants to the interview schedule in the present study was relatively higher than that in other similar studies, indicating good intentions to participate. In the present study, large percentage ( $43.3 \%$ ) of the participants was aged between 36 and 45 years. Similar results were found by other researchers in other countries [3,21].

\subsection{Demographics of the farm workers who participated in the study $(n=300)$}

The mean age $\pm \mathrm{SD}$ of the respondents is $32.5 \pm 7.9$ years. The majority $(60 \%)$ of the participants were male. Results related to the educational levels of the participants showed that $98(32.7 \%)$ had no education and 126 (42\%) studied up to Primary, while the remaining (25.3\%) have secondary level education.

The results showed that $90(30 \%)$ participants were using pesticides in open fields, $210(70 \%)$ in closed fields. In this study, 98 farm workers $(33 \%)$ stated that they had worked with pesticides for less than 1 year. Eighty five (28\%) of the participants reported working for the period of 2 to 5 years with pesticide application whereas $117(39 \%)$ respondents have the experience in usage of pesticide for more than 5 years.

\subsection{Factors influencing pesticide knowledge and practice of safety use of pesticides}

Table-1: Knowledge and Practice on safety use of Pesticides based on their education

\begin{tabular}{|c|c|c|c|c|c|c|}
\hline & Education & $\mathrm{N}$ & Mean & Std. Deviation & F-value & $\mathrm{p}$-value \\
\hline \multirow{4}{*}{$\begin{array}{l}\text { Knowledge on safety use of } \\
\text { pesticides }\end{array}$} & Upto Primary & 98 & $78.316 \mathrm{a}$ & 12.3771 & \multirow{4}{*}{$6.328 * *$} & \multirow{4}{*}{0.002} \\
\hline & Upto Secondary & 126 & $79.934 \mathrm{a}$ & 8.6792 & & \\
\hline & 10th and above & 76 & $83.929 \mathrm{~b}$ & 13.6800 & & \\
\hline & Total & 300 & 81.083 & 12.3728 & & \\
\hline \multirow{4}{*}{$\begin{array}{l}\text { Practice on safety use of } \\
\text { pesticides }\end{array}$} & Upto Primary & 98 & 52.870 & 17.1966 & \multirow{4}{*}{0.233} & \multirow{4}{*}{0.793} \\
\hline & Upto Secondary & 126 & 52.034 & 10.3631 & & \\
\hline & 10th and above & 76 & 51.563 & 10.2635 & & \\
\hline & Total & 300 & 52.188 & 12.9429 & & \\
\hline
\end{tabular}

*Significant @ 5\% level

** Significant@1\% level

From table-1 one can understand that the good knowledge on safety use of pesticides is significantly influenced by education level of farm workers at $1 \%$ level of significance $(p$-value $<0.01)$. Further Duncan's Multiple Range test reveals that the respondents with $10^{\text {th }}$ and above qualification are having $83 \%$ of knowledge which is obviously high and significantly deviating from other educational groups. But level of education has not showed any influence in motivating them to practice safety measures while applying pesticides since $p$-value is $0.793(>0.05)$ in which only $\mathbf{5 0 \%}$ of the safety measures have been taken by them. Hence, it is observed that respondents lacked seriousness to practice perfect measures despite their sufficient knowledge on safety use of pesticides.

Table-2: Knowledge and Practice on safety use of Pesticides based on their age

\begin{tabular}{|c|c|c|c|c|c|c|}
\hline & & & & & & \\
\hline & Age & $\mathbf{N}$ & Mean & Std. Deviation & F-value & p-value \\
\hline \multirow{4}{*}{ Knowledge on safety use of pesticides } & Upto 25 years & 77 & 83.442 & 14.2582 & \multirow{4}{*}{1.968} & \multirow{4}{*}{0.142} \\
\hline & $26-35$ years & 93 & 80.645 & 11.1371 & & \\
\hline & $36-45$ years & 130 & 80.000 & 11.9146 & & \\
\hline & Total & 300 & 81.083 & 12.3728 & & \\
\hline \multirow{4}{*}{ Practice on safety use of pesticides } & Upto 25 years & 77 & 52.273 & 11.9065 & \multirow{4}{*}{1.337} & \multirow{4}{*}{0.264} \\
\hline & $26-35$ years & 93 & 53.831 & 13.0006 & & \\
\hline & $36-45$ years & 130 & 50.962 & 13.4445 & & \\
\hline & Total & 300 & 52.188 & 12.9429 & & \\
\hline
\end{tabular}


Age has no influence on having knowledge practice on safety use of pesticides. Farm workers in all age groups have nearly $80 \%$ of the knowledge as they are practicing only $50 \%$ of the safety measure while using pesticides (Table-2).

Generally the experience of the farmworker shows their maturity, work functioning and perfectness which certainly contribute quality and perfectness in work. Hence, experience of the farmworker in pesticide application has been taken into consideration to know its contribution on knowledge and practice of safety use of pesticides. Results are summarized in table-3.

Table-3: Knowledge and Practice on safety use of Pesticides based on their experience

\begin{tabular}{|c|c|c|c|c|c|c|}
\hline & Experience & $\mathbf{N}$ & Mean & Std. Deviation & F-value & p-value \\
\hline \multirow{4}{*}{ Knowledge on safety use of pesticides } & $<1$ year & 98 & $78.699 \mathrm{a}$ & 6.7659 & \multirow{4}{*}{$7.236^{* *}$} & \multirow{4}{*}{0.001} \\
\hline & $1-5$ years & 85 & $79.265 \mathrm{a}$ & 16.2010 & & \\
\hline & $>5$ years & 117 & $84.402 \mathrm{~b}$ & 12.1620 & & \\
\hline & Total & 300 & 81.083 & 12.3728 & & \\
\hline \multirow{4}{*}{ Practice on safety use of pesticides } & $<1$ year & 98 & $49.872 \mathrm{a}$ & 12.1066 & \multirow{4}{*}{$2.411 *$} & \multirow{4}{*}{0.042} \\
\hline & $1-5$ years & 117 & $53.579 \mathrm{~b}$ & 10.3585 & & \\
\hline & $>5$ years & 85 & $52.941 \mathrm{a}$ & 16.4114 & & \\
\hline & Total & 300 & 52.188 & 12.9429 & & \\
\hline
\end{tabular}

Table-3 exhibits that the experience has shown significant influence on knowledge as well as on practice of farmworkers in which knowledge is positively associated with their experience whereas experience could not influenced their practice much. Interestingly, percentages of placing their knowledge into practice are $63 \%, 68 \%$ and $63 \%$ respectively at three levels of experience. Hence, it is observed that the farmworkers who have low $(<1$ year) and high( $>5$ years) likely to have carelessness in practicing good measures while using pesticides despite their good knowledge.

Table-4: Knowledge and Practice on safety use of Pesticides by gender

\begin{tabular}{|c|c|c|c|c|c|c|}
\hline & Gender & $\mathbf{N}$ & Mean & Std. Deviation & t-value & p-value \\
\hline \multirow{2}{*}{ Knowledge on safety use of pesticides } & Male & 180 & 82.222 & 9.4318 & \multirow{2}{*}{$1.962 *$} & \multirow{2}{*}{0.041} \\
\hline & Female & 120 & 79.375 & 15.6821 & & \\
\hline \multirow{2}{*}{ Practice on safety use of pesticides } & Male & 180 & 51.389 & 13.5643 & \multirow{2}{*}{1.310} & \multirow{2}{*}{0.191} \\
\hline & Female & 120 & 53.385 & 11.9054 & & \\
\hline
\end{tabular}

Table-4 explains the difference between male and female farmworkers with regard to knowledge and practice on safety use of pesticides. p-values evident that the gender has shown significant impact on knowledge but not on practice. Male workers have $82 \%$ of knowledge and significantly differed from female who have only $79 \%$ of knowledge but their practice levels have not differed significantly. Irrespective of their knowledge levels only $50 \%$ of correct measures are followed by both male and female farm workers.

Table-5: Knowledge and Practice on safety use of Pesticides in Open and Closed farms

\begin{tabular}{|c|c|c|c|c|c|c|}
\hline & Type of the farm & $\mathbf{N}$ & Mean & Std. Deviation & t-value & p-value \\
\hline \multirow{2}{*}{ Knowledge on safety use of pesticides } & Closed farms & 210 & 82.679 & 9.9249 & \multirow{2}{*}{$3.474 * *$} & \multirow{2}{*}{0.001} \\
\hline & Open farms & 90 & 77.361 & 16.2164 & & \\
\hline \multirow{2}{*}{ Practice on safety use of pesticides } & Closed farms & 210 & 52.679 & 13.3770 & \multirow{2}{*}{1.004} & \multirow{2}{*}{0.316} \\
\hline & Open farms & 90 & 51.042 & 11.8604 & & \\
\hline
\end{tabular}

Table-5 represents the percentage of farmworkers in the present study who worked in closed fields is higher than of those who worked in open fields. Results reveals that the knowledge of farmworkers in closed farms is more than that of open fields because the nature of closed fields favors the appearance of hazards, and therefore the extensive use of pesticides in such fields exposes the farm workers to a higher risk [20]. 
Table-6: Safety practices in relation to pesticide knowledge

\begin{tabular}{|c|c|c|c|c|}
\hline \multirow{2}{*}{ Safety Practice } & \multicolumn{3}{|c|}{ Level of Practicing safety measures } & \multirow{2}{*}{ Total } \\
\hline & Never & Sometimes & Always & \\
\hline \multirow{2}{*}{$\begin{array}{l}\text { Wearing of protective clothes and gloves } \\
\text { (WPCG) }\end{array}$} & 12 & 111 & 91 & 214 \\
\hline & $5.6 \%$ & $51.9 \%$ & $42.5 \%$ & $71.3 \%$ \\
\hline \multirow{2}{*}{$\begin{array}{l}\text { Wearing of special face mask } \\
\text { (WSFM) }\end{array}$} & 41 & 98 & 119 & 258 \\
\hline & $15.9 \%$ & $38.0 \%$ & $46.1 \%$ & $86.0 \%$ \\
\hline \multirow{2}{*}{$\begin{array}{l}\text { Not eating, drinking and smoking during the } \\
\text { application of pesticides (NEDS) }\end{array}$} & 20 & 95 & 129 & 244 \\
\hline & $8.2 \%$ & $38.9 \%$ & $52.9 \%$ & $81.3 \%$ \\
\hline \multirow{2}{*}{$\begin{array}{l}\text { Reading and following label instructions } \\
\text { (RFLI) }\end{array}$} & 20 & 84 & 96 & 200 \\
\hline & $10.0 \%$ & $42.0 \%$ & $48.0 \%$ & $66.7 \%$ \\
\hline \multirow{2}{*}{$\begin{array}{l}\text { Using leftover pesticide solution in the same } \\
\text { day (ULPS) }\end{array}$} & 4 & 166 & 84 & 254 \\
\hline & $1.6 \%$ & $65.4 \%$ & $33.1 \%$ & $84.7 \%$ \\
\hline \multirow{2}{*}{$\begin{array}{l}\text { Washing hands after pesticide application } \\
\text { (WHAP) }\end{array}$} & 110 & 54 & 136 & 300 \\
\hline & $36.7 \%$ & $18.0 \%$ & $45.3 \%$ & $100.0 \%$ \\
\hline \multirow{2}{*}{$\begin{array}{l}\text { Not keeping the leftover pesticide in drinking } \\
\text { container (WCCS) }\end{array}$} & 21 & 86 & 58 & 165 \\
\hline & $12.7 \%$ & $52.1 \%$ & $35.2 \%$ & $55.0 \%$ \\
\hline \multirow{2}{*}{$\begin{array}{c}\text { Washing contaminated clothes separately } \\
\text { (WSFM) }\end{array}$} & 71 & 79 & 150 & 300 \\
\hline & $23.7 \%$ & $26.3 \%$ & $50.0 \%$ & $100.0 \%$ \\
\hline
\end{tabular}

There is a significant correlation $(r=0.525 ; p<0.001)$ between the knowledge score and the practice score on protective measures. Table- 6 shows that $71.3 \%$ of the participants reported wearing protective clothes and special gloves; among them only $42.5 \%$ are practice the same, $86 \%$ reported wearing of special face mask; among them only $46.1 \%$ are wearing the special face mark while working, $81.3 \%$ reported not eating, drinking and smoking during application of pesticides but only $52.9 \%$ are practicing, out of $66.7 \%$ who reported reading and following label instructions only $48 \%$ are implementing that practice, $84.7 \%$ of the participants indicated that they used leftover pesticide solutions on the same day but only least percentage $33 \%$ are really doing, out of $55.0 \%$ of the participants who knew to not keep the leftover pesticide in a drinking container for later use only $35 \%$ are following. All most all (100\%) participants stated that they wash hands after pesticide application and they used to wash contaminated clothes separately but only 45 to 50 percent are following, which shows the rigorous gap between knowledge and practice. These observations can be viewed in figure-1.

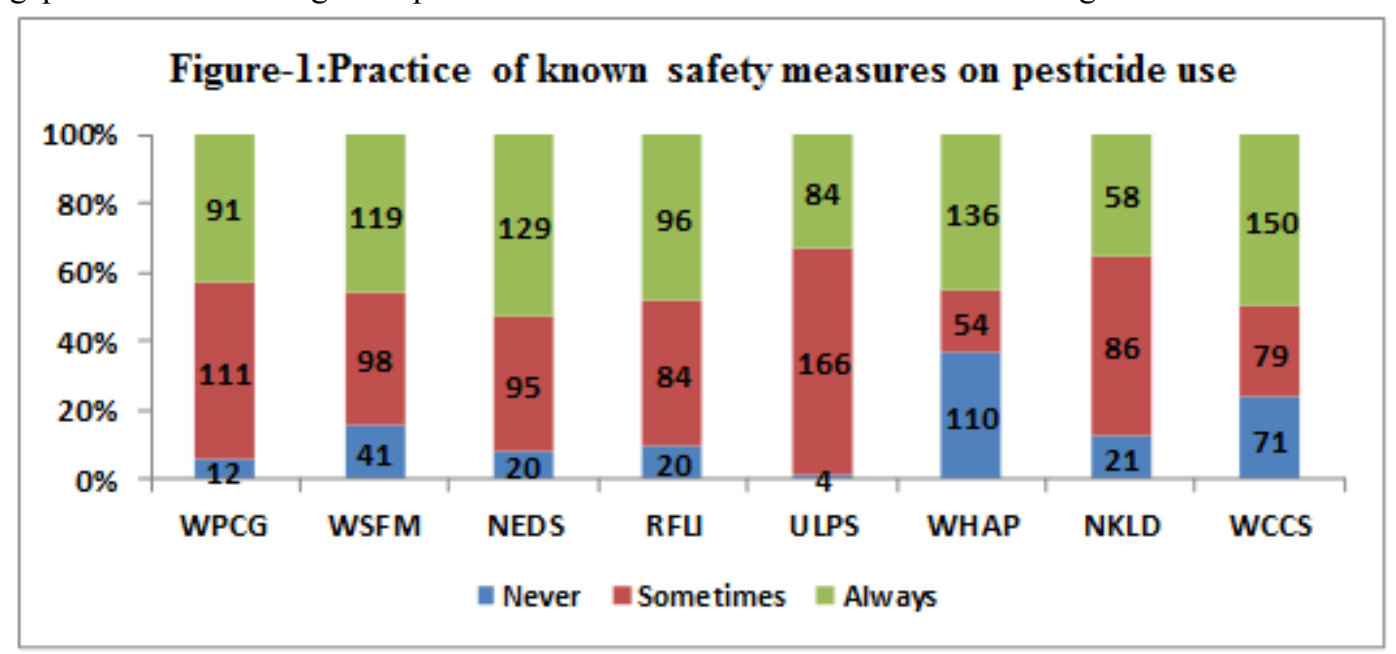

\subsection{Self-reported toxicity symptoms among the farm workers}

Regarding self-reported toxicity symptoms associated with pesticide use, our results showed that common symptoms among the farm workers were skin rash, headache, excessive sweating, and diarrhea only. Present study reports that the most frequent self-reported toxicity symptoms associated with pesticide use were skin rash $(40.5 \%)$, headache $(48 \%)$, excessive sweating $(22.5 \%)$, and diarrhea $(21.3 \%)$. There is a strong significant negative correlation $(r=-0.78 ; p<0.001)$ between self-reported toxicity symptoms and practice score for protective measures. Farm workers with low level of education might be at higher risk when using 
pesticides, possibly due to difficulties in understanding the use instructions and safety procedures included on the product labels because most of them are printed in English.

The WHO has recommended the use of pesticides only by trained people [28]. For the most of pesticides, using protective measures results in a decrease of exposure to pesticides. Similar reductions are seen for farm workers using gloves compared to those not using gloves [14]. The use of protective measures could contribute to decreasing the health effects of pesticides. Also, this would lead, as expected, to a decrease in poisoning prevalence parallel to the reduction in exposure.

Also, this study did not assess treatment for these normally less serious intoxications with symptoms lasting for hours to days. Nevertheless, the results of this study failed to support the hypothesis that farm workers with good knowledge of pesticides might show good practice in pesticide use hence they need proper motivation . Also, farm workers who used pesticides without protective measures could be exposed to pesticides at levels sufficient to be associated with acute health symptoms. Hence, a proper training is needed not to enhance the knowledge but to motivate farmworkers to practice at least known safety measures.

Basic objective of the proper training or education on proper use of pesticides is to ensure that farm workers understand the health hazards of relevant pesticides, use protective equipment properly, practice personal hygiene measures, become familiar with and adopt proper work practices, recognize early symptoms of overexposure to pesticides, and obtain first aid at the earliest time possible.

\section{Conclusions and Recommendations}

Most of the agricultural workers in the study area had a sufficient level of knowledge regarding pesticide use. Particularly, the farm workers seriously unaware of real pesticide risks and they require safety education. Further, education of farm workers has showed influence on having good knowledge in safety use of pesticides, which might avoid intoxication risks but they have poor practice of safety measures. Therefore, it is strongly recommended to initiate special educational programs for the all farm worker prior to engage them for pesticide application. Certain efforts must be placed not only to provide additional knowledge on risks of pesticide use but on the execution of Personal Protective Measures (PPM) which also necessary to decrease the pesticide exposure of farm workers irrespective of their experience in this field of agriculture.

\section{Acknowledgments}

Author is highly grateful to the farmers of Yerpedu mandal of Chittoor district who had helped a lot to collect data from the farm workers who have been engaged in pesticide applications.

\section{References}

[1]. Alavanja M.C., Hoppin J.A., Kamel F.2004. Health effects of chronic pesticide exposure: Cancer and neurotoxicity. Ann. Rev. Publ. Health. 25:155-197.

[2]. Alavanja, M.C.R. et al. 1986. Proportionate Mortality Study of Workers in the Grain Industry. Journal of the National Cancer Institute 78(2): 247-252.

[3]. Atreya K.2007. Pesticide use knowledge and practices: gender differences in Nepal. Environ Res. 104(2):305-311.

[4]. Ciesielski, Stephen; Dana P. Loomis, Susan Rupp Mims, and Anella Auer. 1994. "Pesticide Exposures, Cholinesterase Depression, and Symptoms among North Carolina Migrant Farmworkers." American Journal of Public Health 84(3): 446-451.

[5]. Dasgupta S, Meisner C .2005."Health effects and pesticide perception as determinants of pesticide use: Evidence from Bangladesh World Bank Policy Research Working Paper 3776, November 2005

[6]. Department of Labor. 1988. “Occupational Injury and Illness Incidence Rates by Industry.” Monthly Labor Review: 118-19.

[7]. Environmental Protection Agency (EPA). 1990. "Reducing Risk: Setting Priorities and Strategies for Environmental Protection." September 1990 report of the Science Advisory Board.

[8]. Environmental Protection Agency (EPA). 1993. The Worker Protection Standard for Agricultural Pesticides — How to Comply: What employers need to know. Washington, D.C.: U.S.Government Printing Office Superintendent of Documents.

[9]. Gold, E. and L. Gordis. 1979. "Risk factors for Brain Tumors in Children.” American Journal of Epidemiology 109: 309-319.

[10]. Gunnell D \& Eddleston M .2003 "Suicide by intentional ingestion of pesticides: a continuing tragedy in developing countries". International Journal of Epidemiology 32, 902-909.

[11]. Hoek W, Konradsen F, Athukorala K, Wanigadewa T. 1998. Pesticide poisoning: a major health problem in Sri Lanka. Soc Sci Med :46(4-5):495-504.

[12]. House, J.S.; R.C. Kessler and A.R. Herzog. 1990. “Age, Socioeconomic Status, and Health.” TheMilbank Quarterly 68: 383 -411.

[13]. Kamel F, Engel LS, Gladen BC, Hoppin JA, Alavanja MC, Sandler DP. Neurologic symptoms in licensed private pesticide applicators in the agricultural health study. Environ Health Perspect.2005;113(7):877-882.

[14]. Koh D, Jeyaratnam J. Pesticides hazards in developing countries. Sci Total Environ.1996;188(1):S78-S85.

[15]. Konradsen F, Hoek W, Cole DC, Hutchinson G, Daisley H, Singh S, et al. 2003. Reducing acute poisoning in developing countries - options for restricting the availability of pesticides. Toxicology ;192(2-3):249-261.

[16]. Lowengart, R. and J. Peters. 1987. "Childhood Leukemia and parents' occupational and home exposures." Journal of the National Cancer Institute 79(1): 39-46.

[17]. Manoj Kumar Mohanty, et.al, .2013.Evaluation of Knowledge and Practice of Pesticide use among Agricultural workers in Pondicherry, South India, Journal of Forensic and Legal Medicine, Else wear Publications,

[18]. Muhammad Khan, et.al, 2009. Assessing farmer's Pesticide Safety Knowledge in cotton growing area of Punjab, Pakistan, Online at http://mpra.ub.uni-muenchen.de/16220/MPRA Paper No. 16220, posted 13. July 2009.

[19]. Ohayo-Mitoko GJ, Kromhout H, Simwa JM, Boleij JS, Heederik D. 2000.Self reported symptoms and inhibition of acetylcholinesterase activity among Kenyan agricultural workers. Occup Environ Med;57(3):195-200. 
[20]. Parrón T, Hernández AF, Pla A, Villanueva E. 1996. Clinical and biochemical changes in greenhouse sprayers chronically exposed to pesticides. Hum Exp Toxicol ;15(12):957-963.

[21]. Recena MC, Caldas ED, Pires DX, Pontes ER. 2006. Pesticides exposure in Culturama, Brazil—knowledge, attitudes, and practices. Environ Res;102(2):230-236.

[22]. Schwartz, D.A. and J.P. LoGerfo. 1988. Congenital Limb Reduction Defects in the Agricultural Setting. American Journal of Public Health 78:654-657.

[23]. Singh Divya, Vinay Deepa. 2013. Gender participation in Indian agriculture: An ergonomic evaluation of occupational hazard of farm and allied activities: International Journal of Agriculture, Environment and Biotechnology, Vol.6.Issue.1 pp.157-168.

[24]. Smit LA, van-Wendel-de-Joode BN, Heederik D, Peiris-John RJ, Hoek W. 2003. Neurological symptoms among Sri Lankan farmers occupationally exposed to acetylcholinesterase-inhibiting insecticides. Am J Ind Med;44(3):254-264.

[25]. Stenzel, P.L. 1991. Right-to-know Provisions of California's Proposition 65: Naivete of the Delaney Clause Revisited. Harvard Environmental Law Review 15: 493-528.

[26]. Wesseling C, McConnell R, Partanen T, Hogstedt C. 1997. Agricultural pesticide use in developing countries: health effects and research needs. Int J Health Serv ;27(2):273-308.

[27]. WHO. 1991. World Health Organization, safe use of pesticides. Fourteenth report of the WHO expert committee on vector biology and control. World Health Organ Tech Rep Ser;813:1-27.

[28]. WHO. 2004. World Health Organization, recommended classification of pesticides by hazard and guidelines to classification. Geneva, Switzerland.

[29]. Williams, D.R. 1990. Socioeconomic Differentials in Health: A review and redirection. Social Psychology Quarterly 53:81-99.

[30]. Wilson C, Tisdell C.2001. Why farmers continue to use pesticides despite environmental, health sustainability costs? Ecol Econ;39(3):449-462.

[31]. Wilson C.2000. Environmental and human costs of commercial agricultural production in south Asia. Int J Social Econ;2(8):816846. 